\title{
Long-term outcomes of expanded polytetrafluoroethylene conduits with bulging sinuses and a fan-shaped valve in right ventricular outflow tract reconstruction
}

\author{
Takako Miyazaki, MD, PhD, ${ }^{a}$ Masaaki Yamagishi, MD, PhD, ${ }^{a}$ Yoshinobu Maeda, MD, ${ }^{a}$ \\ Satoshi Taniguchi, MD, ${ }^{a}$ Shuhei Fujita, MD, ${ }^{a}$ Hisayuki Hongu, MD, ${ }^{a}$ and Hitoshi Yaku, MD, PhD ${ }^{b}$
}

\section{ABSTRACT}

Objective: Various types of conduits are available for right ventricular outflow tract (RVOT) reconstruction. We have developed an expanded polytetrafluoroethylene (ePTFE) conduit with bulging sinuses and a fan-shaped ePTFE valve. This study summarized the results of a multicenter study evaluating the valved ePTFE conduit.

Methods: The valve functions of 902 patients (median age, 3.9 years; median weight, $12.6 \mathrm{~kg}$ ) who underwent RVOT reconstruction using valved ePTFE conduits ( 9 different sizes, 8-24 mm in diameter) at 65 hospitals between 2001 and 2015 were retrospectively investigated. Median follow-up time was 5.5 years. The valve functions were assessed using echocardiography, cardiac catheterization, and magnetic resonance angiography.

Results: There were no deaths related to the ePTFE conduit. The peak RVOT gradient was $16.5 \pm 13.1 \mathrm{~mm} \mathrm{Hg}$, and pulmonary insufficiency graded better than mild was $95.9 \%$ at the latest follow-up. Conduit replacement was performed in 55 patients, and in only 3 patients because of conduit infection. Freedom from intervention at 5 years and 10 years was $92.3 \%$ and $76.1 \%$, respectively, with small conduits $(8-16 \mathrm{~mm}$ in diameter) and $99.6 \%$ and $95.1 \%$, respectively, with large conduits (18-24 $\mathrm{mm}$ in diameter).

Conclusions: The long-term outcomes of the ePTFE conduit with a fan-shaped valve and bulging sinuses appear clinically satisfactory. We believe that the longevity of small-sized conduits can yield sufficient time to exchange them to larger-sized conduits without any loss of their valve functions. Regarding longevity and resistance to infections, this ePTFE valved conduit can be one of the best ways to reconstruct the RVOT. ( $\mathrm{J}$ Thorac Cardiovasc Surg

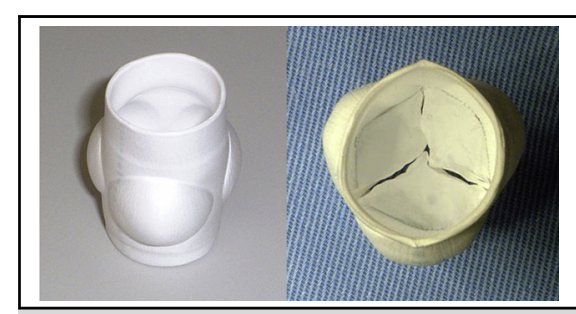

Expanded polytetrafluoroethylene conduits with bulging sinuses and a fan-shaped valve.

\section{Central Message}

The long-term outcomes of the ePTFE conduit with a fan-shaped valve and bulging sinuses appear clinically satisfactory. This ePTFE valved conduit can be one of the best ways to reconstruct the RVOT.

\section{Perspective}

A fan-shaped valve design with bulging sinuses on expanded polytetrafluoroethylene conduits has beneficial effects on long-term valve function. These valves can accomplish excellent long-term outcomes and represent a promising material for right ventricular outflow reconstruction.

See Editorial Commentary page 2577.
A large spectrum of congenital heart diseases requires valved conduits to establish anatomic continuity between the right ventricular outflow tract (RVOT) and the

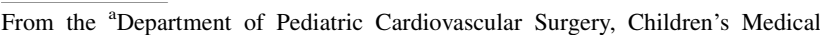
Center, and ${ }^{b}$ Division of Cardiovascular Surgery, Department of Surgery, Kyoto Prefectural University of Medicine, Kyoto, Japan.

This study was approved by the Institutional Review Board of Kyoto Prefectural University of Medicine (RBMR-C-657-1, January 15, 2010).

Read at the 97th Annual Meeting of The American Association for Thoracic Surgery, Boston, Massachusetts, April 29-May 3, 2017.

Received for publication May 20, 2017; revisions received Nov 24, 2017; accepted for publication Dec 24, 2017; available ahead of print March 3, 2018.

Address for reprints: Masaaki Yamagishi, MD, PhD, Department of Pediatric Cardiovascular Surgery, Children's Medical Center, Kyoto Prefectural University of Medicine, Kyoto, Japan (E-mail: myama@koto.kpu-m.ac.jp). $0022-5223 / \$ 36.00$

Copyright $(2018$ by The American Association for Thoracic Surgery https://doi.org/10.1016/j.jtcvs.2017.12.137
}

pulmonary artery. These valves require good performance to maintain good valve function over the long term, especially for younger children. Thus, we focused on the properties of expanded polytetrafluoroethylene (ePTFE); it has good biocompatibility, and its microporous structure impedes cellular penetration and subsequent calcification, which is a common cause of valvular dysfunction.

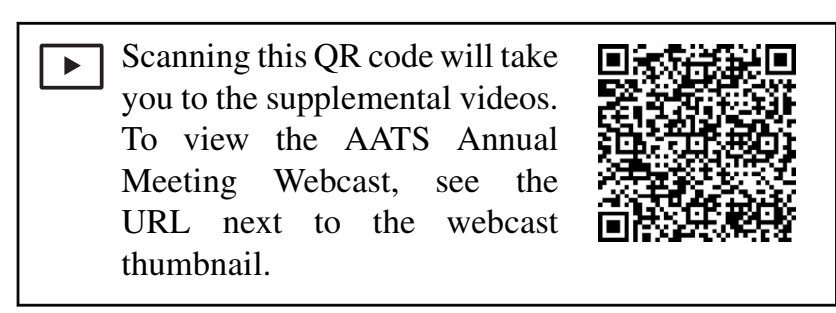




\section{Abbreviations and Acronyms \\ ePTFE = expanded polytetrafluoroethylene \\ IQR = interquartile range \\ PS = pulmonary stenosis \\ RVEDVI $=$ right ventricular end-diastolic volume index \\ RVOT = right ventricular outflow tract}

We have developed handmade ePTFE valves with bulging sinuses and fan-shaped valves, and we previously reported midterm results showing excellent valvular function. ${ }^{1-4}$

In Japan, these valves have been used at 65 institutes given the unavailability of homograft and bovine jugular veins, and they have shown excellent results. All the conduits that were implanted in this study were made at Kyoto Prefectural University of Medicine. Each institute asked us to make the conduits before the operations. We formed bulging sinuses on the conduit automatically using a special machine, and one author personally sutured all the fanshaped valves on all the conduits in the operating room. ${ }^{2,3}$ In addition, all the finished valves were sterilized and delivered to the Japanese institutes as needed. The purpose of this study was to review the clinical outcomes of the ePTFE valved conduit for RVOT reconstruction in a multicenter study (Video 1).

\section{MATERIALS AND METHODS}

This study was approved by the Institutional Review Board at Kyoto Prefectural University of Medicine (RBMR-C-657-1, January 15, 2010).

\section{Data Collection and Statistical Analysis}

This multicenter study included follow-up with each patient at the respective institutes. Preoperative and postoperative data were collected retrospectively from the patients' medical records at each institute. The conduit diameters at the time of insertion were converted into $\mathrm{Z}$-values by regression analysis based on previously published nomograms, ${ }^{5,6}$ and a predicted pulmonary valve size was determined using a historically validated nomogram ${ }^{7}$ indexed to the body surface area.

To assess the presence of pulmonary regurgitation and to determine the mean blood pressure gradients across the valve, all patients periodically underwent transthoracic, 2-dimensional, color flow, M-mode Doppler echocardiography during follow-up at each institute. The grade of the conduit stenosis was determined using continuous Doppler to measure the maximum velocities across the conduit and the pressure gradient across the RVOT. The grades were as follows: mild, peak velocity $<3 \mathrm{~m} / \mathrm{s}$, and peak gradient $<36 \mathrm{~mm} \mathrm{Hg}$; moderate, peak velocity 3 to $4 \mathrm{~m} / \mathrm{s}$, and peak gradient 36 to $64 \mathrm{~mm} \mathrm{Hg}$; and severe, peak velocity $>4 \mathrm{~m} / \mathrm{s}$, and peak gradient $>64 \mathrm{~mm} \mathrm{Hg}$. The degree of pulmonary regurgitation was classified based on a 5 -grade semiquantitative scale $(0$, none; 1 , trivial; 2 , mild; 3 , moderate; or 4 , severe) according to the features of the jet flow as measured with pulsed Doppler echocardiography. All the criteria used for grading were based on the commonly used guidelines for echocardiograms. ${ }^{8}$

All data are expressed as means \pm standard deviation, median, and interquartile range (IQR). The Kaplan-Meier product limit method was used to analyze patient survival and freedom from reoperation.

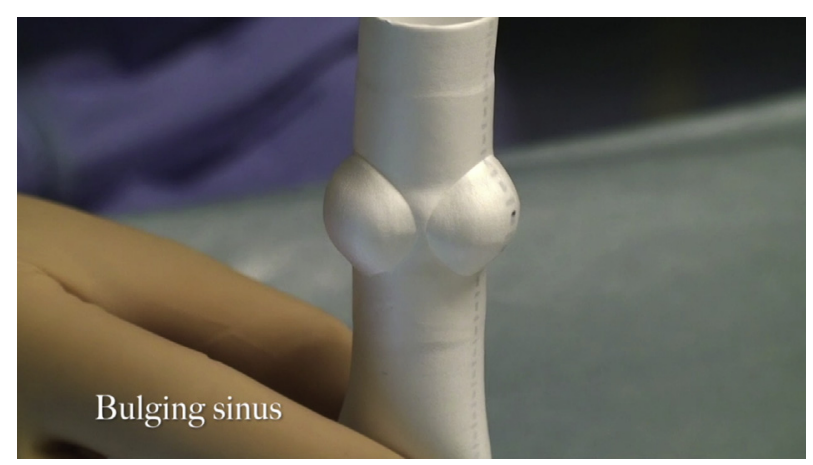

VIDEO 1. How to make the valved conduit. Video available at: http:// www.jtcvsonline.org/article/S0022-5223(18)30310-6/fulltext.

\section{RESULTS}

\section{Patients}

Between February 2001 and January 2015, 902 patients underwent RVOT reconstruction using fan-shaped ePTFE valves and ePTFE valved conduits with bulging sinuses in 65 Japanese institutes. The inclusion criterion was the use of operative treatment as the primary correction for underlying heart disease; patients undergoing palliative procedures were excluded. The anatomic diagnoses are listed in Table 1.

The median age at the time of operation was 3.9 years (range, 0 days to 56.8 years). There were 292 patients $(32.4 \%)$ younger than 2 years. Their median body weight at the time of surgery was $12.6 \mathrm{~kg}(2.1-91.3 \mathrm{~kg})$. Three hundred sixty-four patients $(40.3 \%)$ had previous RVOT reconstruction with prosthetic valves. The diameters of the conduits were $8 \mathrm{~mm}$ in 3 patients, $10 \mathrm{~mm}$ in 24 patients, $12 \mathrm{~mm}$ in 78 patients, $14 \mathrm{~mm}$ in 99 patients, $16 \mathrm{~mm}$ in 196 patients, $18 \mathrm{~mm}$ in 187 patients, $20 \mathrm{~mm}$ in 71 patients, $22 \mathrm{~mm}$ in 175 patients, and $24 \mathrm{~mm}$ in 69 patients. Conduits smaller than $16 \mathrm{~mm}$ were implanted in 400 patients $(44.3 \%)$.

Figure 1, A, shows the patients' body weight and the diameters of the conduits used, and Figure $1, B$, shows the body weights and $\mathrm{Z}$-values. The conduit's $\mathrm{Z}$-value at implantation was $1.3 \pm 1.0$ (median, 1.3; IQR, 0.46-1.89; range, -2.0 to 5.1 ), and its size as a percentage of the normal pulmonary annulus was $135.2 \% \pm 15.4 \%$ (median, 134.8; IQR, 112.4-150.8; range, 90.9\%-237.1\%). Conduit characteristics are listed in Table 2. The Z-value at implantation was $1.8 \pm 0.8$ (median, 1.9; IQR, 1.4-2.3) in patients younger than 2 years and $0.9 \pm 1.0$ (median, 0.8 ; IQR, 0-1.7) for patients older than 2 years.

At the initial construction of the bulging sinuses, the ePTFE graft needs to be formally opened, because the bulging sinuses are formed from flat molds. After the bulging sinus has been formed and the fan-shaped valve anastomosed, the graft is rolled up and sutured to form a conduit (Figure 2, A). ${ }^{2}$ Starting in 2010, it was no longer necessary to cut open the ePTFE because of improved fabrication techniques (Figure 2, B). ${ }^{3}$ 
TABLE 1. Anatomic diagnoses

\begin{tabular}{lcc}
\hline \multicolumn{1}{c}{ Diagnosis } & Procedure & Number of patients \\
\hline TOF/DORV/VSD + PA & $\begin{array}{c}\text { Construction of } \\
\text { RV-PA continuity }\end{array}$ & 374 \\
TOF/DORV/VSD + PS & & 144 \\
TOF + APV & 36 \\
PA + IVS & & 8 \\
TGA + PS & & 25 \\
cTGA + PA & & 16 \\
cTGA + PS & & 24 \\
Truncus arteriosus & Ross or Ross-Konno & 87 \\
Others & procedure & 89 \\
Subtotal & & 803 \\
AS & & 32 \\
\multicolumn{1}{c}{ ASR } & & 20 \\
AR & & 99 \\
Other & & 902 \\
\hline Subtotal & & 2 \\
Total & & \\
\hline
\end{tabular}

$T O F$, Tetralogy of Fallot; $D O R V$, double-outlet right ventricle; $V S D$, ventricular septal defect; $P A$, pulmonary atresia; $R V$, right ventricle; $P S$, pulmonary stenosis; $A P V$, absent pulmonary valve; $I V S$, intact ventricular septum; $T G A$, transposition of the great arteries; $C T G A$, corrected transposition of the great arteries; $A S$, aortic stenosis; $A S R$, aortic stenosis with regurgitation; $A R$, aortic regurgitation.

Median follow-up time was 5.5 years (range, 0-15.2). Overall, 439 patients $(48.7 \%)$ underwent postoperative cardiac catheterization, and 77 patients $(8.5 \%)$ underwent postoperative magnetic resonance imaging. For the 887 patients, confidence interval data for the most recent echocardiograms and cardiac catheterization measurements were obtained.

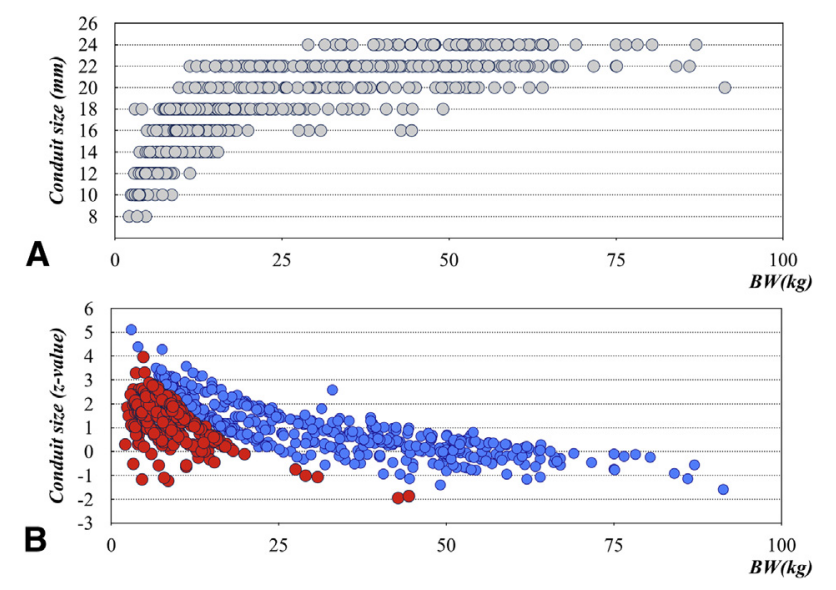

FIGURE 1. Conduit size. A, Patient body weight and conduit diameters. B, Patients' body weight and Z-values of the conduit. Blue circles indicate a large conduit $(18-24 \mathrm{~mm})$, and red circles indicate a small conduit (8-16 mm). $B W$, Body weight.

\section{Mortality}

The early mortality rate within 30 days after conduit implantation was $1.7 \%(n=15)$, with 8 patients dying of heart failure, 3 patients dying of respiratory failure, 2 patients dying of infection, 1 patient dying of pulmonary hypertension crisis, and 1 patient dying of other causes. The late mortality rate beyond 30 days after conduit implantation was $2.4 \%(n=22)$, with 3 patients dying of heart failure, 2 patients dying of respiratory failure, 8 patients dying of infection, 3 patients dying of sudden death, and 6 patients dying of unknown causes; however, these were not related to the valves. The overall survival rate was $96.1 \%$ at 5 years, $95.3 \%$ at 10 years, and $95.3 \%$ at 15 years (Figure 3 ).

\section{Conduit Replacement}

Fifty-five patients $(6.1 \%)$ required explantation of the conduits. The cause of explantation of the conduits was somatic growth in 12 patients, peripheral pulmonary stenosis (PS) in 10 patients, and valvular PS in 10 patients, with a concomitant procedure in 8 patients, infection in 7 patients (with conduit infection in 3 patients and infections involving other parts, such as the tricuspid valve, ventricular septal defect patch, central venous catheter, and RVOT, in 4 patients), RVOT stenosis in 3 patients, suspicion of coronary artery compression in 1 patient, and unknown cause in 2 patients. Freedom from conduit replacement was $96.3 \%$ at 5 years, $87.4 \%$ at 10 years, and $84.2 \%$ at 15 years (Figure 4, A). Examining freedom from conduit replacement by conduit diameter, the rates for 8- to 16-mm-diameter conduits were $92.3 \%$ at 5 years, $76.1 \%$ at 10 years, and $71.9 \%$ at 12 years; for 18 - to $24-\mathrm{mm}$-diameter conduits, the rates were $99.6 \%$ at 5 years, $95.1 \%$ at 10 years, and $92.6 \%$ at 15 years (Figure $4, B$ ). In addition, examining freedom from conduit replacement by patient age at the time of conduit implantation, the rates for those younger than 2 years were $90.0 \%$ at 5 years, $73.7 \%$ at 10 years, and $67.0 \%$ at 12 years; for those 2 years old or older, the rates $99.2 \%$ at 5 years, $92.8 \%$ at 10 years, and $90.9 \%$ at 15 years (Figure 3, C). There were no valves placed in these conduits using a catheter-based approach.

\section{Percutaneous Transluminal Angioplasty for Pulmonary Stenosis}

Fifty-three patients $(5.9 \%)$ required a catheter intervention, including 37 balloon dilatations for pulmonary artery bifurcation stenosis, 8 for valvular stenosis, and 9 for peripheral pulmonary artery stenosis.

\section{Conduit Function}

Conduit function was evaluated at the latest follow-up at a median time of 4.8 years. The degree of pulmonary regurgitation was none in 213 patients $(24.0 \%)$, trivial in 331 patients $(37.3 \%)$, mild in 304 patients $(34.3 \%)$, 
TABLE 2. Conduit characteristics

\begin{tabular}{|c|c|c|c|c|c|}
\hline \multicolumn{6}{|c|}{ Conduit characteristics $(n=902)$} \\
\hline Conduit size (mm) & Number of patients & Age & Body weight (kg) & $\mathrm{Z}$ value & $\%$ of normal size \\
\hline 8 & 3 & $3.0 \pm 2.6 \mathrm{mo}$ & $3.3 \pm 1.3$ & $-0.5 \pm 0.7$ & $103.6 \pm 16.2$ \\
\hline 10 & 24 & $2.3 \pm 15.3 \mathrm{mo}$ & $3.6 \pm 1.6$ & $1.0 \pm 0.8$ & $129.9 \pm 15.8$ \\
\hline 12 & 78 & $6.1 \pm 7.0 \mathrm{mo}$ & $5.4 \pm 1.7$ & $1.3 \pm 1.7$ & $130.4 \pm 14.3$ \\
\hline 14 & 99 & $1.4 \pm 1.5 \mathrm{y}$ & $7.8 \pm 2.4$ & $1.4 \pm 0.7$ & $132.6 \pm 13.3$ \\
\hline 16 & 196 & $2.3 \pm 2.5 \mathrm{y}$ & $9.9 \pm 5.5$ & $1.7 \pm 0.9$ & $138.1 \pm 14.1$ \\
\hline 18 & 187 & $3.9 \pm 4.0 \mathrm{y}$ & $12.5 \pm 7.4$ & $1.9 \pm 1.1$ & $143.6 \pm 18.6$ \\
\hline 20 & 71 & $11.0 \pm 9.7 \mathrm{y}$ & $30.4 \pm 15.7$ & $0.3 \pm 1.1$ & $125.9 \pm 15.0$ \\
\hline 22 & 175 & $13.3 \pm 8.7 y$ & $37.8 \pm 15.5$ & $0.6 \pm 1.0$ & $132.8 \pm 12.8$ \\
\hline 24 & 69 & $16.7 \pm 8.0 \mathrm{y}$ & $52.0 \pm 12.2$ & $0.5 \pm 0.5$ & $136.2 \pm 5.7$ \\
\hline
\end{tabular}

moderate in 38 patients $(4.3 \%)$, and severe in only 1 patient $(0.1 \%)$ during the follow-up period (Figure $5, A)$.

The mean peak pressure gradient between the pulmonary artery and right ventricle was $16.5 \pm 13.1 \mathrm{~mm} \mathrm{Hg}$ (median, 13.0; IQR, 7-21; range, 0-72.9 mm Hg). Conduit stenosis was graded as being mild or less in 808 patients $(91.1 \%)$, moderate in 64 patients $(7.2 \%)$, and severe in 15 patients $(1.7 \%)$ during the follow-up period (Figure 5, B).

The right ventricular end-diastolic volume index (RVEDVI) was measured in 308 patients, and it was more than $150 \mathrm{~mL} / \mathrm{m}^{2}$ in 8 patients $(2.6 \%)$ and more than $170 \mathrm{~mL} / \mathrm{m}^{2}$ in 3 patients $(1.0 \%)$.

\section{Histologic Examination}

Ten conduits removed for conduit exchange were examined histologically. Some of them showed a small amount of

A
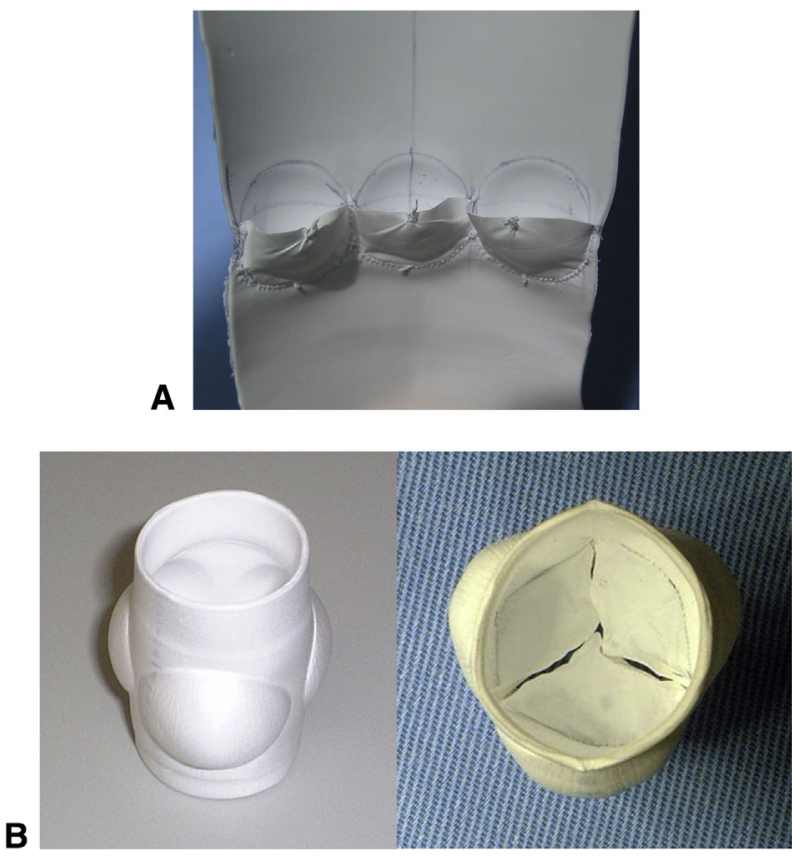

FIGURE 2. A, A former version of a valved conduit. B, A new version of a valved conduit. lymphohistiocytic inflammation that multifocally covered the surfaces of the conduit and leaflet. The interstices of the leaflet, conduit, and suture associated with the leaflet attachment region were mildly and multifocally mineralized, and the microscopic image showed that the areas of leaflet mineralization disrupted the ePTFE membrane (Figure 6).

\section{DISCUSSION}

A range of materials including homografts, bovine jugular veins (Contegra; Medtronic, Minneapolis, Minn), autologous pericardium, Hancock porcine pulmonary valves (Medtronic), Dacron grafts, and mechanical valves have been used for RVOT reconstruction. Homografts and bovine jugular veins are commonly used, but early degeneration and calcification are inevitable complications. ${ }^{9}$ Unfortunately, their long-term availability and durability are unsatisfactory. ${ }^{10-12}$ Furthermore, Albanesi and colleagues ${ }^{12}$ reported that the incidence of Contegra infection was $11.3 \%$ (12 of 106 patients), which is relatively high. In contrast, infection of the ePTFE conduit occurred in only 3 patients $(0.3 \%)$ who required conduit replacement, a very low incidence. We use only cefazolin sodium at the time of skin incision and every 6 hours for

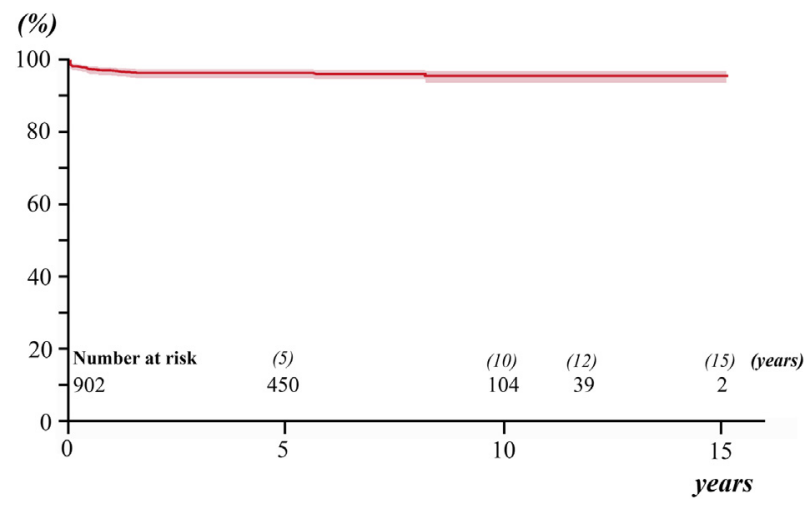

FIGURE 3. Kaplan-Meier survival curves. 

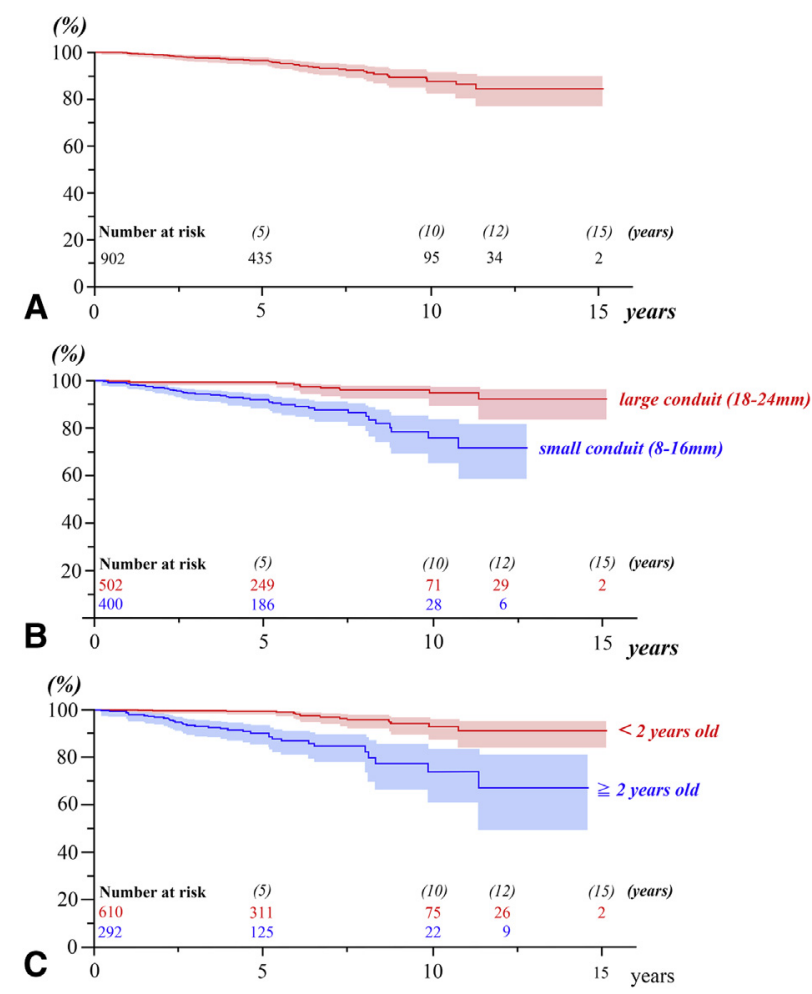

FIGURE 4. Kaplan-Meier freedom from conduit exchange. A, Overall freedom from conduit exchange. B, Freedom from conduit exchange by conduit diameter. C, Freedom from conduit exchange by patient age at the time of conduit implantation.

24 hours. In regard to longevity and resistance to infections, this ePTFE valved conduit is the best choice for RVOT reconstruction.
In engineering experiments using a pediatric right heart stimulator with a pneumatic artificial heart, the existence of bulging sinuses demonstrated a lower energy loss at the valve, a larger effective opening area, and a faster response in valve movement. Hydrodynamic experiments of various combinations of valve shapes and conduit configurations have demonstrated that the largest flow is measured in the conduit with a combination of a fan-shaped valve and a sinus of Valsalva, especially with a fan-shaped valve. In addition, the lowest pressure gradient through the valve is measured in the conduit with a combination of a fan-shaped valve and a sinus of Valsalva, especially with a bulging sinus. Energy loss is extremely low in the fanshaped valve group. Thus, good valve function can be expected to a certain extent with a fan-shaped ePTFE valve alone, and the use of a fan-shaped ePTFE valve is recommended even if the sinus cannot be constructed. However, the bulging sinus appears to be effective for the closing motion of the valve. Therefore, the combination of a fanshaped valve and a bulging sinus may contribute to valve function. ${ }^{13}$

Invariably, patients who had a smaller conduit had a higher likelihood of needing reoperation. Vitanova and coworkers ${ }^{14}$ reported on the durability of homografts, Contegra, and Hancock conduits that were $15 \mathrm{~mm}$ or less in diameter. The rates of freedom from conduit exchange at 5 years were $69.4 \% \pm 6.6 \%, 59.4 \% \pm 8.7 \%$, and $53.8 \% \pm 7.4 \%$ for homografts, Contegra, and Hancock conduits, respectively. The rates of freedom from conduit exchange at 10 years were $38.1 \% \pm 8.3 \%$, $38.0 \% \pm 11.3 \%$, and $20.3 \% \pm 7.5 \%$ for homografts,

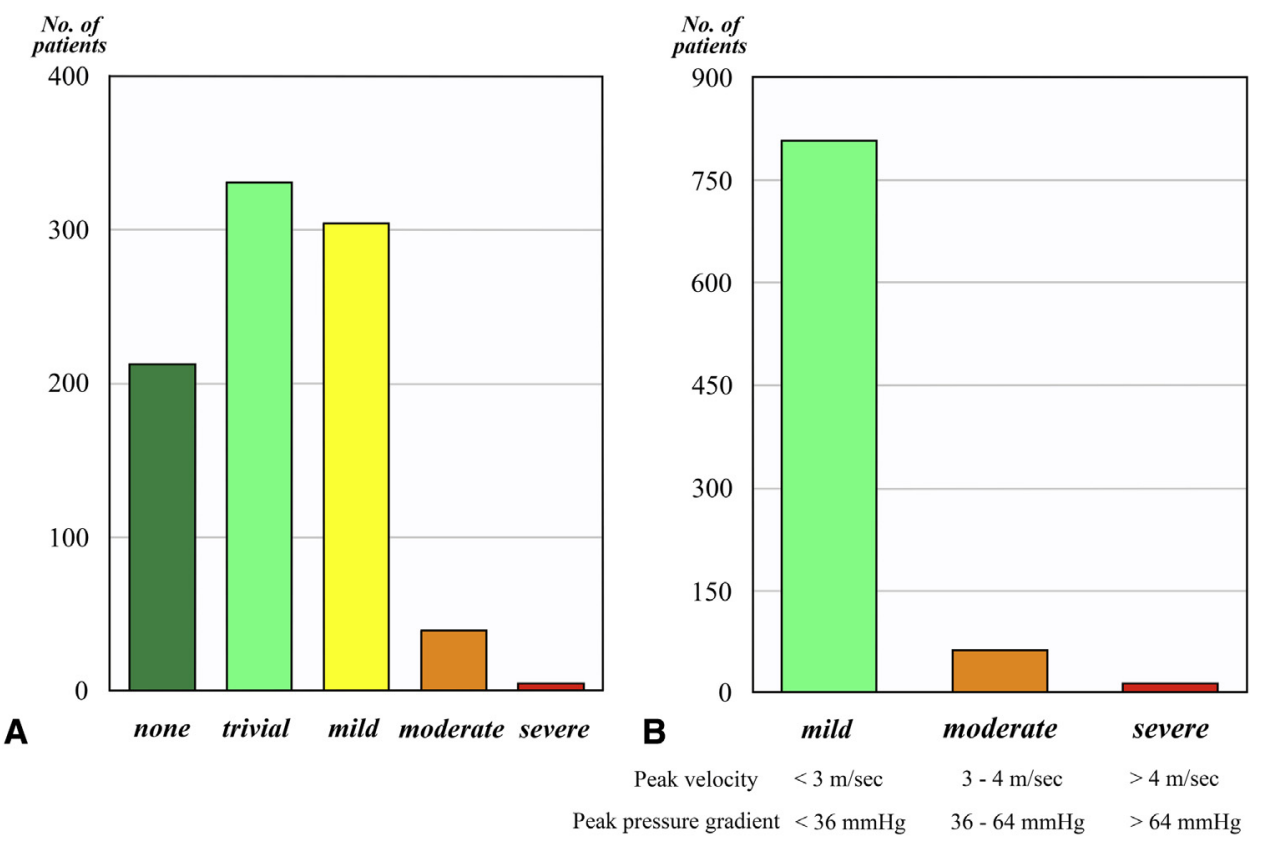

FIGURE 5. A, Pulmonary regurgitation. B, Conduit stenosis. 

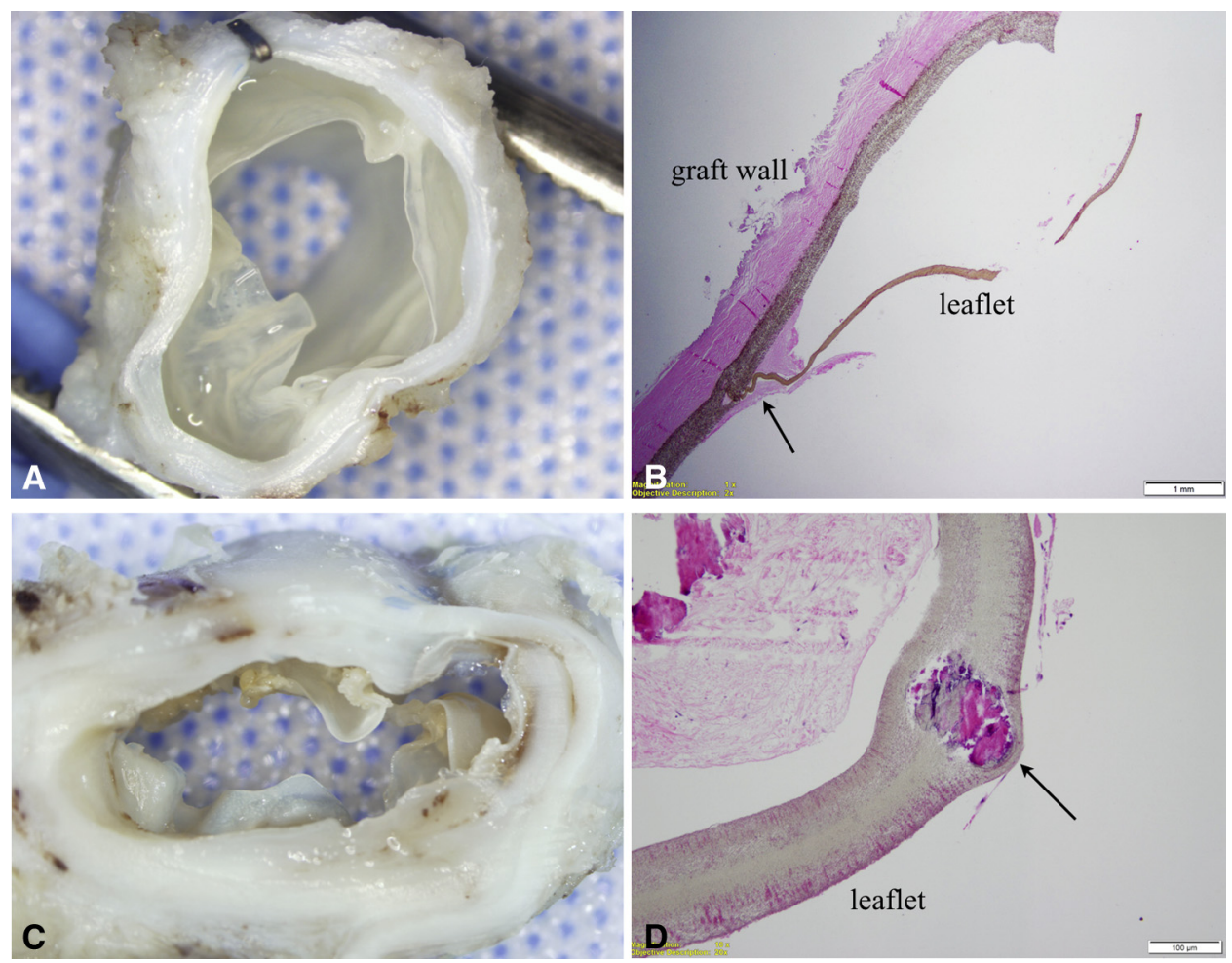

FIGURE 6. Histologic examination. A, A 10-mm expanded polytetrafluoroethylene (ePTFE) conduit with a bulging sinus and tricuspid ePTFE valve 1.4 years after implantation. The leaflet is clear. B, Middle section stained with hematoxylin and eosin (H\&E). The valve leaflet was attached to the conduit with ePTFE suture and was bound in a serpentine pattern by the surrounding neointima. C, A 22-mm ePTFE conduit with a bulging sinus and tricuspid ePTFE valve 10 years after implantation. There are multifocal, variably sized and -shaped exophytic concretions. D, Specimen stained with H\&E. Areas of leaflet mineralization disrupt the ePTFE microstructure (black arrow).

Contegra, and Hancock conduits, respectively. On the other hand, for the ePTFE valved conduit with a diameter of 8 to $16 \mathrm{~mm}$, the rates of freedom from conduit exchange were $92.3 \%$ at 5 years, $76.1 \%$ at 10 years, and $71.9 \%$ at 12 years; these were excellent results. In addition, for smaller-sized conduits, the optimal size was controversial; in our previous study, for smaller-sized conduits, we proposed that the first choice of a conduit for RVOT reconstruction should be an ePTFE conduit with a Z-score around $1.4 .{ }^{15}$ Of the 27 patients with 8- to $10-\mathrm{mm}$ conduits, 6 were neonates. Early death occurred in 2 patients, and late death occurred in $4 \mathrm{pa}-$ tients; 4 patients required replacement of conduits at a median time of 2.5 years (range, 1.0-5.2 years). Excellent longevity of small-sized conduits enables us to have enough time to exchange them to larger-sized conduits without loss of their valve function.

In addition, we use patches with bulging sinuses and a fan-shaped valve in the case of tetralogy of Fallot or other congenital cardiac disorders with a narrow pulmonary annulus. Conduits were chosen for patients with pulmonary atresia, truncus arteriosus, or Ross candidates who had discontinuity between the RV and the pulmonary artery. Conduits were also used in adolescents and adults who needed pulmonary valve replacements and in patients with right heart dysfunction who needed to have pulmonary regurgitation prevented completely.

Meyns and colleagues ${ }^{16}$ reported a high incidence of severe anastomosis and site stenosis of Contegra conduits. In the present series, 37 patients $(4.1 \%)$ required percutaneous transluminal angioplasty for anastomosis site stenosis, which is relatively low. However, the ePTFE conduit is harder than a homograft or bovine jugular vein, and to prevent anastomosis site stenosis, a special technique must be used to anastomose it with the native pulmonary artery. If stenosis is present in the left and right pulmonary arteries, augmentation is performed using autologous pericardium or a cut-out ePTFE graft patch. If the difference between the calibers of the pulmonary artery and the conduit is large, turbulent blood flow can occur at the anastomosis and give rise to decreased blood flow energy and stenosis caused by intimal proliferation. Consequently, if stenosis is present near the pulmonary artery bifurcation, it should be augmented to the greatest extent possible. ${ }^{17} \mathrm{We}$ also reported that a conduit with a Z-score greater than or equal to 1.4 could increase the risk of anastomosis site stenosis. ${ }^{15}$

The indication for pulmonary valve replacement owing to pulmonary regurgitation was RVEDVI greater than $150 \mathrm{~mL} /$ $\mathrm{m}^{2}$, with no patients "spontaneously" remodeling to normal 
right ventricle volume if undergoing an operation when RVEDVI was greater than $170 \mathrm{~mL} / \mathrm{m}^{2} .{ }^{18}$ In this series, only 8 patients $(2.6 \%)$ had RVEDVI greater than $150 \mathrm{~mL} /$ $\mathrm{m}^{2}$, and only 3 of them $(1.0 \%)$ had RVEDVI greater than $170 \mathrm{~mL} / \mathrm{m}^{2}$; however, all of them showed pulmonary regurgitation that was no greater than mild. That is, our conduit prevents pulmonary regurgitation and protects right ventricular function. With the growth of the adult population with congenital heart disease, pregnancy becomes an issue because of volume overload of the right ventricle in female patients. The conduit could help the right ventricle to tolerate the higher pressures during vaginal delivery. Therefore, these valves might be suitable for female patients who want to have children. In addition to preventing pulmonary regurgitation, fluid dynamically, because the flow rate is high on the greater curvature side, it is important to position one valve on that side to the greatest extent possible. The distal end of the greater curvature side is severed obliquely so that one valve is on the greater curvature side, and that side is slightly longer. ${ }^{17}$

There were some cases in which the ePTFE conduits were compressed by the sternum. If the sinuses and valve are placed near the original pulmonary valve annulus, which is near the RVOT, there is a risk that the sinuses and the body of the conduit will be compressed and flattened by the sternum. Consequently, the ePTFE valve has to be positioned slightly to the pulmonary atresia side of the original annulus (Video 2). ${ }^{17}$

From the histologic examination results, it can be inferred that the mineralization of the interstices of the leaflet, conduit, and suture associated with the leaflet attachment region may lead to compromised mobility of the leaflet, and the lymphohistiocytic inflammation might provoke mineralization. Because ePTFE has a microporous structure, which impedes cellular penetration, it might be difficult to prevent mineralization completely. However, calcification in the ePTFE material is very small compared with other bioprosthetic valves. Improvement and development of the

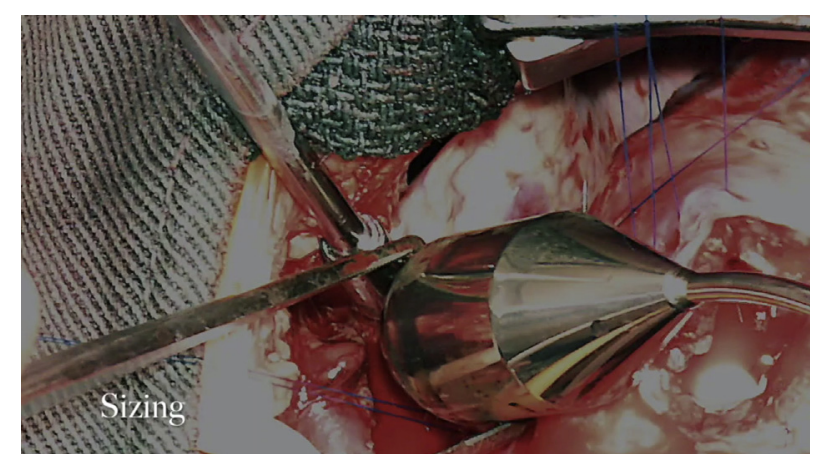

VIDEO 2. Operative procedure. Rastelli procedure using a 14-mm conduit. Video available at: http://www.jtcvsonline.org/article/S00225223(18)30310-6/fulltext.
ePTFE material itself to avoid mineralization are necessary to obtain better valvular function over the long term. The development of the ePTFE material is greatly anticipated. Therefore, to maintain good biocompatibility of the ePTFE and good valve function, we must determine the cause of degeneration in the ePTFE valved conduit. We give aspirin for 6 months and no warfarin after the operation. However, if the lymphohistiocytic inflammation might provoke mineralization, we should probably give aspirin longer.

Although further improvements such as prevention of calcification are needed to obtain better long-term outcomes, the use of ePTFE conduits with bulging sinuses and the fan-shaped ePTFE valves is associated with high freedom from reoperation and prevention of pulmonary insufficiency, which makes this a promising approach to RVOT reconstruction.

\section{CONCLUSIONS}

The fan-shaped valve with bulging sinuses on ePTFE conduits has beneficial effects on long-term valve function in RVOT reconstruction. These valves can provide excellent long-term outcomes even for infants and younger children, and they can offer a promising approach to RVOT reconstruction.

\section{Webcast}

You can watch a Webcast of this AATS meeting presentation by going to: https://aats.blob.core.windows.net/ media/17AM/2017-05-01/RM312/05-01-17_Room312_ 1400_Miyazaki.mp4.

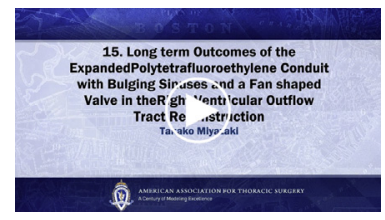

\section{Conflict of Interest Statement}

Dr Yamagishi receives personal fees from W.L. Gore \& Associates, Inc, as a consultant. All other authors have nothing to disclose with regard to commercial support.

The authors are grateful to all the institutions that were included in this study for providing data for this manuscript.

\section{References}

1. Yamagishi M, Kurosawa H, Nomura K, Kitamura N. Fan-shaped expanded polytetrafluoroethylene valve in the pulmonary position. J Cardiovasc Surg (Torino). 2002;43:779-86.

2. Miyazaki T, Yamagishi M, Nakashima A, Fukae K, Nakano T, Yaku H, et al. Expanded polytetrafluoroethylene valved conduit and patch with bulging sinuses in right ventricular outflow tract reconstruction. J Thorac Cardiovasc Surg. 2007; 134:327-32.

3. Miyazaki T, Yamagishi M, Maeda Y, Yamamoto Y, Taniguchi S, Sasaki Y, et al. Expanded polytetrafluoroethylene conduits and patches with bulging sinuses and fan-shaped valves in right ventricular outflow tract 
reconstruction: multicenter study in Japan. J Thorac Cardiovasc Surg. 2011;142:1122-9.

4. Shinkawa T, Tang X, Gossett JM, Mustafa T, Hategekimana F, Watanabe F, et al. Valved polytetrafluoroethylene conduits for right ventricular outflow tract reconstruction. Ann Thorac Surg. 2015;100:129-37.

5. Daubeney PE, Blackstone EH, Weintraub RG, Slavik Z, Scanlon J, Webber SA Relationship of the dimension of cardiac structures to body size: an echocardiographic study in normal infants and children. Cardiol Young. 1999;9:402-10.

6. Kirklin JW, Blackstone EH, Jonas RA, Kouchoukos NT. Anatomy, dimensions, and terminology. In: Kirklin JW, Barratt-Boyes BG, eds. Cardiac Surgery. 3rd ed. Edinburgh: Churchill Livingstone; 2004:50.

7. Rowlatt UF, Rimoldi HJ, Lev M. The quantitative anatomy of the normal child's heart. Pediatr Clin North Am. 1963;10:499-588.

8. Baumgartner H, Hung J, Bermejo J, Chambers JB, Evangelista A, Griffin BP, et al. Echocardiographic assessment of valve stenosis: EAE/ASE recommendations for clinical practice. Eur J Echocardiogr. 2009;10:1-25.

9. Boethig D, Thies WR, Hecker H, Breymann T. Midterm course after pediatric right ventricular outflow tract reconstruction: a comparison of homografts, porcine xenografts and Contegras. Eur J Cardiothorac Surg. 2005;27:58-66.

10. Homann M, Haehnel JC, Mendler N, Paek SU, Holper K, Meisner H, et al. Reconstruction of the RVOT with valved biological conduits: 25 years experience with allografts and xenografts. Eur J Cardiothorac Surg. 2000;17:624-30.

11. Stulak JM, Dearani JA, Burkhart HM, Connolly HM, Warnes CA, Suri RM, et al. The increasing use of mechanical pulmonary valve replacement over a 40-year period. Ann Thorac Surg. 2010;90:2009-15.

12. Albanesi F, Sekarski N, Lambrou D, Segesser LKV, Berdajs DA. Incidence and risk factors for Contegra graft infection following right ventricular outflow tract reconstruction: long-term results. Eur J Cardiothorac Surg. 2014;45:1070-4.

13. Shiraishi Y, Suzuki I, Yabe S, Sugai TK, Yamada A, Kameyama T, et al. Engineering assessment of expanded polytetrafluoroethylene cardiac valve with bulging sinus. Jpn J Artif Organs. 2010;39:S-62.

14. Vitanovaa K, Cleuzioua J, Horera J, Kasnar-Sampreca J, Vogtb M, Schreibera C, et al. Which type of conduit to choose for right ventricular outflow tract reconstruction in patients below 1 year of age? Eur J Cardiothorac Surg. 2014;46:961-6.

15. Yamashita E, Yamagishi M, Miyazaki T, Maeda Y, Yamamoto Y, Kato N, et al. Smaller-sized expanded polytetrafluoroethylene conduits with a fan-shaped valve and bulging sinuses for right ventricular outflow tract reconstruction. Ann Thorac Surg. 2016;102:1336-44.

16. Meyns B, Garsse LV, Boshoff D, Eyskens B, Mertens L, Gewillig M, et al. The Contegra conduit in the right ventricular outflow tract induces supravalvular stenosis. J Thorac Cardiovasc Surg. 2004;128:834-40.

17. Yamagishi M. Right ventricular outflow reconstruction using a polytetrafluoroethylene conduit with bulging sinuses and tricuspid fan-shaped polytetrafluoroethylene valve. Operative Techniques Thorac Cardiovasc Surg. 2017; 21:211-29.

18. Therrien J, Provost Y, Merchant N, Williams W, Colman J, Webb G. Optimal timing for pulmonary valve replacement in adults after tetralogy of Fallot repair. Am J Cardiol. 2005;95:779-82.

Key Words: right ventricular outflow tract reconstruction, ePTFE valved conduit, bulging sinus, fan-shaped valve

\section{Discussion}

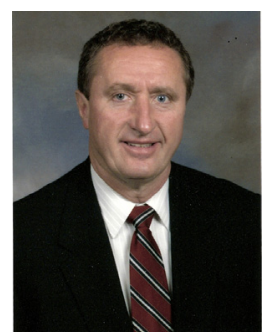

Dr John W. Brown (Indianapolis, Ind). I would like to congratulate Dr Miyazaki and Professor Yamagishi and their colleagues for a beautifully illustrated presentation and a well written manuscript which they provided to me in advance of this meeting. In addition, they provided me with a video of how they put their valved conduit together, which I enjoyed. I was fortunate to have attended the Tokyo STS meeting a couple of months ago and I saw some of their outcome data and was quite impressed.

Our Japanese colleagues have not had allografts for RV PA construction and until quite recently did not have the jugular conduit. These two conduits are the most popular conduits in the US and in Europe. So the old proverb holds true: "necessity is the mother of invention."

The Japanese have developed and constructed their own PTFE valved conduit and have been achieving excellent results for nearly 15 years. Professor Yamagishi, now from Kyoto, was the first surgeon to demonstrate that the $0.1-\mathrm{mm}$ PTFE membrane that was designed and marketed for pericardial closure could be used to make a synthetic pulmonary valve leaflet, and he first published his results with this material as a monocusp in 1993. Our group in Indiana adopted this material 24 years ago, and we continue to use the Gore-Tex monocusp outflow tract patch for RVOT reconstruction in those tetralogy patients requiring transannular incisions.

Today, they have summarized their outcomes in 902 patients with a valved conduit that is handmade by a single surgeon, and they supply this conduit to 65 other institutions in Japan in nine different sizes ( $8 \mathrm{~mm}$ up to $24 \mathrm{~mm}$ ). These handmade conduits were implanted between 2001 and 2015 in children and adults and have shown excellent function. Patient survival, as stated, was quite good, at $95 \%$ out to 15 years. Their results, particularly in the group less than 2 years of age, were quite impressive, with a freedom from reoperation of $90 \%, 74 \%$, and $67 \%$ at 5, 10, and 15 years, which, to my knowledge, are the best results published for an RV PA conduit in this age group of less than 2 years. Freedom from conduit replacement in the group receiving larger conduits was greater than $90 \%$ at 15 years. Their conduit showed excellent freedom from stenosis as well as regurgitation during their follow-up. However, 55 of their conduits have been explanted and 53 have undergone balloon dilatation, and I think this confirms that no conduit in the RV PA position is perfect.

This large Japanese experience with a handmade conduit is not likely to be transferrable to American surgeons or to our European colleagues because our governing bodies (FDA) are likely to frown on individual surgeons making their own valved conduits and/or supplying them to their friends.

I have 4 short questions and I will ask them one at a time. (1) Since you introduced the PTFE as a monocusp 25 years ago and have had good success with your valved conduit, have you stopped using monocusps for Tetralogy that requires a transannular patch?

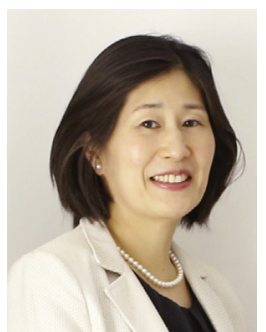

Dr Takako Miyazaki (Kyoto, Japan). I appreciate your comment, and I would like to answer your questions. Conduits were chosen for patients with pulmonary atresia, truncus arteriosus or Ross candidates who had discontinuity between the right ventricle and the pulmonary artery. Conduits were also used in other adolescents and adults who needed pulmonary valve replacements 
and in the patients with right heart dysfunction who needed to prevent complete pulmonary regurgitation.

On the other hand, we used patches in the case of tetralogy of Fallot or other congenital cardiac disorders with narrow pulmonary annulus, as you did.

Dr Brown. Thank you. You may not be able to answer this question, but it would seem that for the rest of the pediatric $\mathrm{CV}$ community, industry ought to pick up on your technique and methods and produce a similar conduit that all of us could use. I don't know whether you want to make a comment about somebody else manufacturing these except for you and Dr Yamagishi.

Dr Miyazaki. I'm sorry, but I have no comment.

Dr Brown. The next question is more of a practical one. Does it matter where and how you orient the conduit valve in your patients who receive the conduit? Where do you put the valve and how do you orient the commissures in the conduit?

Dr Miyazaki. Fluid dynamically, because the flow rate is high on the greater curvature side, it is important to position one valve on that side to prevent pulmonary regurgitation to the greatest extent possible. The distal end of the greater curvature side is placed obliquely so that one valve is on the greater curvature side and that side is slightly longer.

If the sinuses and valve are placed near the original pulmonary areas annulus, which is near the RVOT, there is a risk that the sinuses and the body of the conduit will be compressed and threatened flattened by the sternum. Consequently, the ePTFE valve has to be positioned slightly to the pulmonary artery side of the original annulus.

Dr Brown. Thank you. And what is your anticoagulation strategy for this conduit?

Dr Miyazaki. We only use aspirin for 6 months, no Coumadin [warfarin].

Dr Brown. And do you recommend SBE prophylaxis while this conduit is in place in your patients?

Dr Miyazaki. We only use antibiotics at the time of incision of the skin and every 6 hours within 24 hours. The ePTFE itself may resist infection, I think.

Dr Brown. I would like to congratulate you and your coauthors for a very nice presentation and for adding this conduit to our toolbox for RV PA reconstruction in the future. Thank you.

Dr Miyazaki. Thank you very much.

Dr Daywood Kamal Mehsood

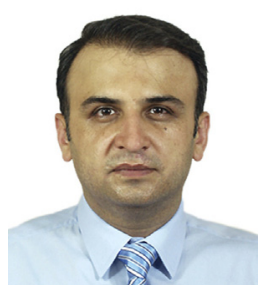

(Birmingham, United kingdom). Thank you very much. That was a nice presentation. I have two questions.

A: As we know, with this PTFE material the needle holes bleed profusely, especially when doing Fontans. So do you augment your suture line with any Teflon or with a strip of pericardium, just to stop the bleeding on the distal and the proximal end?

B: You mentioned about following your conduit in terms of stenosis and the patients growing out of the size of their conduit. Have you followed your conduits in terms of regurgitation at 5,10 , and 15 years, how many of these valves have been competent at 5,10 , and 15 years?

Dr Miyazaki. Thank you very much for your questions. First?

Dr Mehsood. The bleeding, about the bleeding. Do you secure the suture line with anything else or you just sew it directly to the pulmonary artery and to the RVOT?

Dr Miyazaki. We sew the conduit directly to the pulmonary artery using CV-6 ePTFE suture and to the RVOT using CV-5 ePTFE suture, and we use glue to the suture line to prevent bleeding. We use neither autologous pericardium nor any other material.

Dr Mehsood. And regurgitation, how many of these valves have been competent at $5,10,15$ years?

Dr Miyazaki. Pulmonary regurgitation?

Dr Mehsood. Yes, because you have followed these conduits more in terms of stenosis and the patient growing out of the size of the conduit and not in the regurgitation. So, I am just interested how much these valves will be competent over 5,10 and 15 years.

Dr Miyazaki. Indeed, there were no patients who needed conduit explantation due to pulmonary regurgitation. So, we think these conduits might prevent pulmonary regurgitation for a long time.

Dr Mehsood. Thank you.

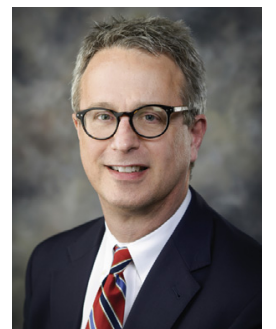

Dr Robert Jaquiss (Dallas, Tex). I would like to poll the audience. These are absolutely spectacular results for a problem that we all see all the time. The conduits that we have available to us here in the Third World of the United States are biologic conduits that are prone to infection. In the case of Contegra, none of them grow, they all calcify, some of them cause allosensitization, which can make subsequent interventions more difficult, et cetera. Dr Brown suggested that we may be hampered by our regulatory agencies from the kind of progress that we would like to make, and that may very well be correct.

But if we had these conduits available to us in North America, just by a show of hands, how many people in the audience would use this as a conduit of first choice?

(Show of hands).

Dr Jaquiss. I don't know how many people in the audience are not from North America, so it's a little hard to calculate a denominator there.

Kirk Kanter has presented several times the use of a Gore-Tex conduit in the Fontan operation in a way that is absolutely off label, turning it upside down and enlarging one of the limbs, and has remarked that the company has been unwilling to buy into that. I suspect the Gore company or their competitors would likewise be unwilling to offer commercial versions of the conduits we have heard about today.

On the other hand, we do all sorts of things off label all of 
the time, and I think it might be worth us taking a trip to Japan to learn how to make these conduits. For myself I certainly am now very interested in having a second reason to go to Japan.

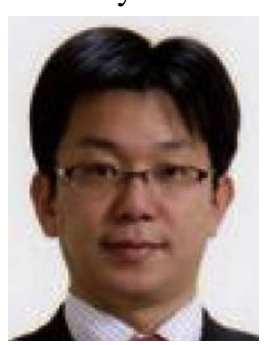

Dr Takeshi Shinkawa (Little Rock, Ark).

I was trained under Dr Yamagishi 15 years ago before I came to the US, and in Arkansas we are applying the exact same product with the Kyoto group, and we can reproduce a very good outcome.

Regarding the use in the US, we get IRB approval from our institution. We asked the FDA if it is okay to deform the already commercial product and the FDA was okay. They said it fit into our scope of practice. As long as you make it and use it, it should be fine.

Dr Jaquiss. So the FDA, Bram Zuckerman is fond of saying they are not in the business of regulating the practice of medicine. So if, like Arkansas, you have someone on your campus who knows how to make these things, maybe we will hear a North American version of this.

Thank you very much.

Dr Miyazaki. Thank you very much. 